\title{
Cora de Moura Pedreira (1915-2005)
}

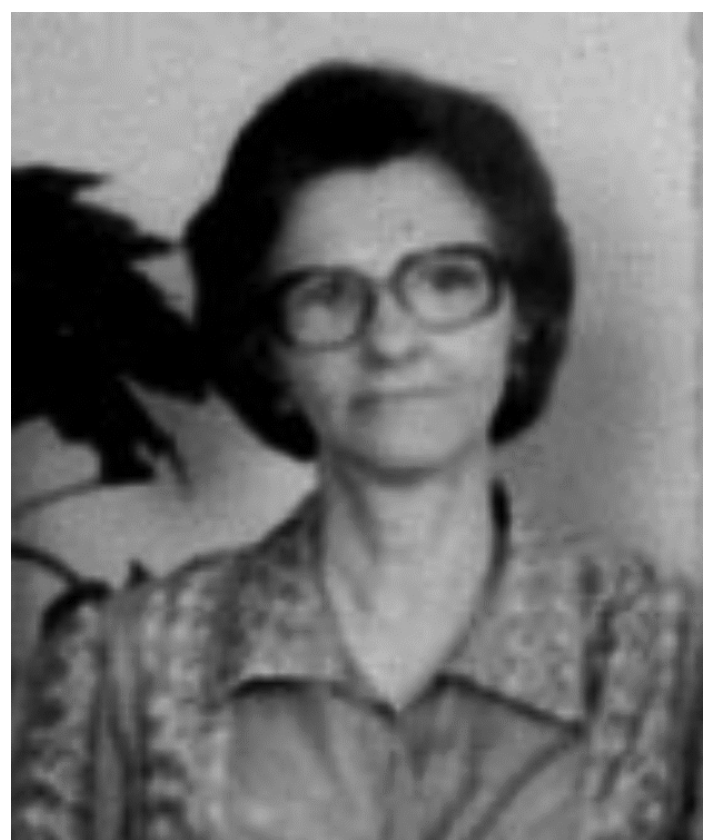

On April $7^{\text {th }}, 2005$, the geneticist Cora de Moura Pedreira passed away at the age of 90 years, in Salvador, Bahia. Born in the inland of that State, Cora de Moura Pedreira moved to Salvador when she was still a child and graduated there in 1938 in Medico-Surgical Sciences from the School of Medicine of Bahia. She attended postgraduation courses in the fields of Biology, Medicine and Genetics, both in Brazil and abroad. Dr. Cora Pedreira's medical degree did not interfere with her interest in research in other fields besides Medicine. So, when the Institute of Biology of UFBA (The Federal University of Bahia) was created and a Laboratory of Human Genetics was set up there, the conditions had been established for her students to initiate research in this field. Thus, new researchers were formed in Bahia. At the Institute of Biology, Prof. Cora de Moura Pedreira was Head of the Department of General Biology and later Director of this Unit.

One of the pioneers in Human Genetics research in Brazil, she presented in 1954 her Doctor's thesis entitled "Rh-Hr Factors: aspects of their research in Bahia". Proceeding with her activities in Human Genetics, Dr. Pedreira investigated native Brazilian communities such as the Mundurucú in the Tapajós River region in Pará, the Pataxó

Profa. Dra. Lilia Maria de Azevedo Moreira, Universidade Federal da Bahia, Instituto de Biologia, Departamento de Biologia Geral, Universidade Federal da Bahia, Salvador, Bahia, Brazil. in the Colônia River Valley in Bahia, the Canela and Guajajara in Maranhão, the Kraô in Goiás, the Kariri-Mirandela in Bahia, besides the Negroid-Helvetia population in Bahia, and a Northeastern community in Paulo Afonso, also in Bahia.

Prof. Cora Pedreira attended courses and internships in Brazilian and international research centers: an Intensive Course of Cytogenetics (1942); a Perfecting and Specialization course in Tuberculosis (DNS, 1944); an Internship at the Center of Genetic Research of the General Biology Chair at "Faculdade Nacional de Filosofia da Universidade do Brasil" (National School of Philosophy of the University of Brazil) (1951); a Course of Hematology (ABM, 1953); an Internship at the Department of Biology of the School of Philosophy, Sciences and Arts of the University of São Paulo (1953); Courses on Health Education, Public Health and Botany at the University of Chile (1955); a Course of Leprology (FAMED, 1956); an Internship at the Human Genetics Department of the University of Michigan, USA (1958); a Course on Biological Physics (CECIBA, 1966); a "Genetics Review" Course (UFBA, 1967); a Course of Human Genetics (SBG UFBA, 1970); an Internship as a Visiting Professor of UNESCO in the Bioanthropology Laboratory of the "Faculté de Sciences" of the University of Paris (1974); an Internship in the Bioanthropology Laboratory of the "Faculté de Sciences" of the University of Paris VII (1974); an Internship at the Primatology Center of the University of Turin, Italy (1974), and at the Institute of Fundamental Biology - Department of Cytogenetics of the "Universidad Autónoma" of Barcelona, Spain (1974).

Thanks to her working capacity and leadership, she was able to attract young researchers, among which Professor Lucy Isabel S. Peixoto, who became interested in the Genetics of Brazilian Populations. This led to the foundation, in 1959, of the first Human Genetics Laboratory of UFBA, located first at the "Hospital das Clínicas" and nowadays at the Institute of Biology.

The progress of Human and Animal Cytogenetics, brought about by the temporary culture of peripheral blood lymphocytes stimulated by phytohemagglutinin that was developed in the sixties, enabled Prof. Cora Pedreira to set up cytogenetics at the Institute of Biology of UFBA, thus starting several researches, mainly in Primates of the New World. Among the theses and dissertations resulting from these investigations the most outstanding is "The karyotype of the Black Tufted-Ear Marmoset (Callithrix penicillata, 
Elliot 1913)", presented in 1970 by Prof. Pedreira herself when applying for the position of Full Professor at the same Institute. Her scientific production on blood groups, hereditary anemias, anthropogenetics, twin studies, medical genetics and cytogenetics was published in Brazilian as well as international journals and in the proceedings of scientific congresses.

In addition to coordinating numerous research works in the above mentioned laboratory, Professor Cora de Moura Pedreira was a member of several scientific societies, such as the Brazilian Society of Genetics (Sociedade Brasileira de Genética - SBG), of which she was a founding member, the Brazilian Society for the Progress of Science (SBPC), where she was a Counselor for several two-year terms, and the Latin-American Society of Genetics (ALAG), of which she was also a founding member.

Dr. Cora de Moura Pedreira's trajectory is an example of indefatigable activity in research and college teaching, which enabled her to foster the formation of new researchers and the development of genetics in the State of Bahia. 